\title{
HUBUNGAN SIKAP KERJA DUDUK DENGAN KELUHAN NYERI PUNGGUNG BAWAH PADA PEKERJA YANG MENGGUNAKAN KOMPUTER
}

\author{
Heni Fa'riatul Aeni* Awaludin ${ }^{* *}$
}

\begin{abstract}
ABSTRAK
World Health Organization (WHO) mengatakan bahwa 2\%-5\% dari karyawan di negara industri tiap tahun mengalami Nyeri Punggung Bawah (NPB). Sebanyak 90\% kasus nyeri punggung bukan disebabkan oleh kelainan organik, melainkan oleh kesalahan posisi tubuh dalam bekerja. Menggunakan komputer yang dilakukan dalam posisi duduk dalam waktu yang lama berisiko mengalami keluhan nyeri punggung bawah. Tujuan penelitian ini untuk mengetahui hubungan sikap kerja duduk dengan keluhan nyeri punggung bawah pada pekerja yang menggunakan komputer di Kantor Kesehatan Pelabuhan Kelas II Bandung tahun 2017. Jenis penelitian adalah survei analitik dengan rancangan cross-sectional. Populasi dalam penelitian ini adalah semua pekerja yang menggunakan komputer di Kantor Kesehatan Pelabuhan Kelas II Bandung tahun 2017 sebanyak 59 orang dan pengambilan sampel menggunakan metode total sampling. Pengambilan data penelitian dengan menggunakan observasi dan wawancara. Instrumen untuk pengambilan data dalam penelitian ini adalah lembar kuesioner dan lembar observasi. Analisa data menggunakan analisa univariat dengan persentase dan bivariat dengan uji Spearman Rho. Hasil penelitian menunjukkan bahwa sikap kerja duduk sebagian besar responden dengan dalam kategori sedang yaitu 29 orang $(47,5)$ dan keluhan nyeri punggung bawah dalam kategori rendah yaitu 30 orang $(50,8 \%)$. Hasil uji spearman rho menunjukan bahwa nilai $\mathrm{p}$ value $=0,010$, maka $\mathrm{p}$ value $<\alpha$ $(0,05)$ berarti Ho ditolak artinya ada hubungan yang signifikan antara sikap kerja duduk dengan keluhan nyeri punggung bawah pada pekerja yang menggunakan komputer.
\end{abstract}

Kata Kunci : : Sikap Kerja Duduk, Nyeri Punggung Bawah

\begin{abstract}
World Health Organization (WHO), says that 2\% -5\% of employees in industrialized countries each year to experience the Lower Back Pain (LBP). As many as $90 \%$ of cases of back pain is not caused by organic disorder, but by mistake body position at work. Using a computer that is done in a sitting position for a long time at risk of low back pain. The purpose of this study to determine the relationship sitting working attitude with complaints of low back pain in workers who use computers at the Harbor Health Office of Class II Bandung in 2017. This type of research is analytic survey research with cross-sectional design. The population in this study were all employees who use computers at the Port Health Office Class II Bandung in 2017 as many as 59 people and sampling using total sampling method. Data retrieval research using observation and interviews. Instruments for data collection in this study is a questionnaire and observation sheet Data were analyzed using univariate analysis with percentages and bivariate Spearman Rho test.

The results showed that the attitude of the sit-down with the majority of respondents in the medium category is 29 (47.5) and low back pain in the low category were 30 people (50.8\%). Spearman rho test results showed that the $p$ value $=0.010$, then the $p$ value $<\alpha(0.05)$ means that Ho refused meaning that there is a significant correlation between sitting working attitude with complaints of low back pain in workers who use computers.
\end{abstract}

Keywords $\quad$ : Sitting Working Attitude, Low Back Pain

\footnotetext{
*Staf Pengajar Program Studi S1 Kesehatan Masyarakat STIKes Cirebon

** Alumni PSKM STIKes Cirebon Tahun 2017
} 


\section{PENDAHULUAN}

Perkembangan dunia perindustrian di era globalisasi semakin pesat. Hal ini membuat persaingan antara industri besar, industri menengah dan industri kecil semakin ketat. Persaingan yang ketat membuat para pelaku industri berlomba-lomba untuk meningkatkan kualitas Sumber Daya Manusia (SDM) yang dimiliki perusahaan sehingga mampu meningkatkan kualitas produk yang dihasilkan oleh perusahaan tersebut. Hal ini akan berhasil jika berbagai risiko yang akan mempengaruhi kehidupan para pekerja dapat diantisipasi. Berbagai risiko tersebut adalah kemungkinan terjadinya Penyakit Akibat Kerja (PAK), penyakit yang berhubungan dengan pekerjaan dan kecelakaan kerja yang dapat menyebabkan kecacatan dan kematian. ${ }^{1}$

Salah satu penyakit akibat kerja (PAK) adalah nyeri punggung bawah atau Low Back Pain (LBP) yang disebabkan oleh posisi duduk yang salah pada saat bekerja yaitu sindroma klinik yang ditandai dengan gejala utama nyeri atau perasaan lain yang tidak enak didaerah tulang punggung bagian bawah. ${ }^{2}$ Nyeri punggung bawah merupakan fenomena yang seringkali dijumpai pada setiap pekerjaan. Insiden dan beratnya gangguan nyeri punggung bawah lebih sering dijumpai pada pekerja wanita dibandingkan laki-laki. Posisi statis dalam bekerja kadang-kadang tidak dapat terhindarkan. Bila keadaan statis tersebut berlangsung terus-menerus atau berulang-ulang maka dapat menyebabkan gangguan kesehatan antara lain nyeri punggung bawah. Nyeri punggung bawah yang timbul dapat mengakibatkan kehilangan jam kerja sehingga menggangu produktivitas kerja. ${ }^{3}$

World Health Organization (WHO) mengatakan bahwa 2\%-5\% dari karyawan di negara industri tiap tahun mengalami Nyeri Punggung Bawah (NPB), dan $15 \%$ dari absenteisme di industri baja serta industri perdagangan disebabkan karena NPB. Data statistik Amerika Serikat memperlihatkan angka kejadian sebesar 15\%-20\% per tahun. Sebanyak 90\% kasus nyeri punggung bukan disebabkan oleh kelainan organik, melainkan oleh kesalahan posisi tubuh dalam bekerja. Nyeri pinggang menyebabkan lebih banyak waktu hilang dari pada pemogokan kerja sebanyak 20 juta hari kerja karenanya. ${ }^{4}$

Kesehatan merupakan keadaan sejahtera dari badan, jiwa dan sosial yang memungkinkan setiap orang hidup produktif secara sosial dan ekonomis pada saat bekerja. Pekerja memerlukan posisi yang baik pada saat melakukan pekerjaannya yaitu dengan posisi duduk. Akibat dari duduk lama dan statis pada pekerja akan menimbulkan ketegangan pada vertebralis terutama pada lumbar. Dalam melakukan pekerjaan, pekerja dituntut menggunakan beberapa posisi tubuh seperti, posisi duduk tegak (statis), posisi duduk membungkuk dan posisi setengah duduk. ${ }^{5}$

Tuntutan pekerjaan yang tinggi sering tidak dapat dihindari dan pekerja sering mengalami nyeri pada anggota tubuhnya. Nyeri merupakan pengalaman sensori dan emosional yang tidak menyenangkan akibat dari kerusakan jaringan yang aktual dan potensial sehingga sangat mengganggu dan menyulitkan lebih banyak orang mengalami nyeri. ${ }^{6}$

Sistem kerja yang tidak ergonomis dalam suatu perusahaan seringkali kurang mendapat perhatian atau dianggap sepele oleh para pihak manajemen atau pengelola sumber daya manusia di perusahaan tersebut. Sebagai contoh antara lain adalah pada cara, sikap dan posisi kerja yang tidak benar, fasilitas kerja yang tidak sesuai, dan faktor lingkungan kerja yang tidak mendukung. ${ }^{7}$

Penyusunan tempat kerja dan tempat duduk yang sesuai harus diatur sedemikian sehingga tidak ada pengaruh yang berbahaya bagi kesehatan. Tempat-tempat duduk yang cukup dan sesuai harus disediakan untuk pekerja-pekerja dan pekerja harus diberi kesempatan yang cukup untuk menggunakannya. Cara bekerja harus diatur sedemikian rupa sehingga tidak menimbulkan ketegangan otot, kelelahan yang berlebihan atau gangguan kesehatan yang lain. ${ }^{8}$ 
Bekerja pada kondisi yang tidak ergonomis dapat menimbulkan berbagai masalah, antara lain: nyeri, kelelahan bahkan kecelakaan. Hal ini didukung hasil penelitian Sakinah (2012) menyatakan bahwa terdapat hubungan antara sikap tubuh dengan keluhan nyeri punggung bawah. ${ }^{4}$ Hasil penelitian Tangkeallo (2013) juga menyatakan bahwa posisi duduk memiliki hubungan yang bermakna dengan keluhan nyeri punggung bawah. ${ }^{9}$ Hasil penelitian Hidayat (2013) juga menyimpulkan bahwa faktor risiko ergonomi dapat mempengaruhi munculnya keluhan muskuloskeletal terhadap pekerja. Semakin tidak ergonomis suatu pekerjaan maka akan memicu terjadinya keluhan muskuloskeletal dengan tingkat keluhan lebih tinggi. Oleh karena itu di tempat kerja perlu diterapkan sistem kerja secara ergonomis. ${ }^{1}$

Ergonomi merupakan suatu ilmu, seni dan penerapan teknologi untuk menyerasikan atau menyeimbangkan antara segala fasilitas yang digunakan baik dalam beraktifitas maupun istirahat dengan segala kemampuan, kebolehan dan keterbatasan manusia baik secara fisik maupun mental sehingga dicapai suatu kualitas hidup secara keseluruhan yang lebih baik. ${ }^{10}$ Risiko potensi bahaya ergonomi akan meningkat dengan tugas monoton, berulang atau kecepatan tinggi; dengan postur tidak netral atau canggung; bila terdapat pendukung yang kurang sesuai; bila kurang istirahat yang cukup. ${ }^{8}$

Berdasarkan hasil survey awal yang dilakukan melalui wawancara di Kantor Kesehatan Pelabuhan Kelas II Bandung diperoleh data dari 10 orang, 5 orang pekerja menyatakan bahwa mengalami nyeri daerah punggung bawah setelah bekerja menggunakan komputer selama sehari karena memiliki posisi kerja yang lebih banyak duduk, yaitu selama 7-8 jam sehari dengan diselingi istirahat selama 1 jam, terkadang karena banyaknya pekerjaan pegawai melakukan penambahan jam kerja atau lembur selama 2-3 jam.

Berdasarkan penelitian terdahulu dan uraian latar belakang di atas peneliti tertarik untuk melakukan penelitian mengenai "Hubungan Sikap Kerja Duduk Dengan Keluhan Nyeri Punggung Bawah Pada Pekerja Yang Menggunakan Komputer di Kantor Kesehatan Pelabuhan Kelas II Bandung tahun 2017”.

\section{METODE PENELITIAN}

Jenis penelitian ini adalah penelitian survei analitik dengan rancangan cross-sectional. Variabel bebas (independent) dalam penelitian ini adalah sikap kerja duduk sedangkan variabel terikat (dependent) adalah keluhan nyeri punggung bawah.

Populasi dalam penelitian ini adalah semua pekerja yang menggunakan komputer di Kantor Kesehatan Pelabuhan Kelas II Bandung tahun 2017 sebanyak 59 orang. Teknik sampling yang digunakan adalah total sampling yaitu semua anggota populasi dijadikan sebagai sampel penelitian. ${ }^{11}$ Maka sampel yang diambil dalam penelitian ini yaitu semua pekerja yang menggunakan komputer di Kantor Kesehatan Pelabuhan Kelas II Bandung tahun 2017 sebanyak 59 orang dengan kriteria sampel sebagai berikut:

Kriteria Inklusi

1) Pekerja dapat berkomunikasi dengan baik.

2) Pekerja bersedia menjadi responden.

3) Pekerja hadir saat penelitian dilaksanakan.

Kriteria Eksklusi

1) Pekerja yang mengalami gangguan jiwa.

2) Pekerja yang mengalami gangguan kesadaran.

Instrumen yang digunakan dalam penelitian ini untuk pengukuran variabel sikap kerja duduk menggunakan lembar observasi Rapid Entire Body Assessment (REBA) dan untuk variabel keluhan nyeri punggung bawah menggunakan lembar kuesioner Nordic Body Map. ${ }^{12}$

Pengumpulan data dalam penelitian ini dilakukan dengan wawancara dan observasi menggunakan lembar kuesioner dan lembar observasi untuk mengumpulkan data langsung dari responden. 
Analisis data univariat yang digunakan dalam penelitian ini adalah analisis data deskriptif dalam bentuk distribusi frekuensi untuk mendeskripsikan variabel sikap kerja duduk dan variabel keluhan nyeri punggung bawah.

Analisis bivariat dilakukan terhadap dua variabel yang diduga berhubungan, dengan tujuan untuk melihat hubungan antara variabel independen dengan variabel dependen. Uji statistik yang digunakan adalah Spearman Rho, karena kedua jenis variabel dengan skala ordinal. Taraf signifikansi yang digunakan adalah (95\%) dengan nilai kemaknaan (5\%). Apabila $\boldsymbol{p}$ Value $\leq$ dari $\alpha(0,05)$, maka Ho ditolak artinya ada hubungan antara variabel bebas dengan variabel terikat. Apabila $\boldsymbol{p}$ Value $>$ dari $\alpha(0,05)$, maka Ho gagal ditolak artinya tidak ada hubungan antara variabel bebas dengan variabel terikat.

\section{HASIL PENELITIAN}

\section{Sikap Kerja Duduk}

Berdasarkan hasil analisis data sikap kerja duduk pada pekerja yang menggunakan komputer di Kantor Kesehatan Pelabuhan Kelas II Bandung tahun 2017 terhadap 59 responden secara deskriptif dapat dilihat pada tabel 1 sebagai berikut:

Tabel 1. Distribusi Frekuensi Sikap Kerja Duduk Pada Pekerja

\begin{tabular}{ccc}
\hline Sikap Kerja Duduk & Frekuensi & Persentase (\%) \\
\hline Tidak Berisiko & 0 & 0 \\
Risiko Rendah & 6 & 10,2 \\
Risiko Sedang & 28 & 47,5 \\
Risiko Tinggi & 14 & 23,7 \\
Risiko Sangat Tinggi & 11 & 18,6 \\
\hline Total & 59 & 100 \\
\hline
\end{tabular}

Berdasarkan tabel 1, menunjukkan bahwa dari 59 responden dengan sikap kerja duduk dalam kategori risiko rendah yaitu 6 orang $(10,2 \%)$, risiko sedang yaitu 28 orang $(47,5)$, risiko tinggi yaitu 14 orang $(23,7)$ dan risiko sangat tinggi yaitu 11 orang $(18,6 \%)$.

\section{Keluhan Nyeri Punggung Bawah}

Berdasarkan hasil analisis data keluhan nyeri punggung bawah pada pekerja yang menggunakan komputer di Kantor Kesehatan Pelabuhan Kelas II Bandung tahun 2017 terhadap 59 responden secara deskriptif dapat dilihat pada tabel 2 sebagai berikut:

Tabel 2. Distribusi Frekuensi Keluhan Nyeri Punggung Bawah

\begin{tabular}{ccc}
\hline Keluhan Nyeri Punggung Bawah & Frekuensi & Persentase (\%) \\
\hline Rendah & 30 & 50,8 \\
Sedang & 29 & 49,2 \\
Tinggi & 0 & 0 \\
Sangat Tinggi & 0 & 0 \\
\hline Total & 59 & 100 \\
\hline
\end{tabular}

Berdasarkan tabel 2, menunjukkan bahwa dari 59 responden dengan keluhan nyeri punggung bawah dalam kategori rendah yaitu 30 orang $(50,8 \%)$ dan sedang yaitu 29 orang $(49,2 \%)$.

\section{Hubungan Sikap Kerja Duduk dengan Keluhan Nyeri Pinggang Bawah}

Berdasarkan hasil analisis uji Spearman Rho untuk mengetahui hubungan antara sikap 
kerja duduk dengan keluhan nyeri punggung bawah pada pekerja yang menggunakan komputer di Kantor Kesehatan Pelabuhan Kelas II Bandung tahun 2017 disajikan dalam tabel 3 :

Tabel 3. Hubungan Sikap Kerja Duduk Dengan Keluhan Nyeri Punggung Bawah

\begin{tabular}{|c|c|c|c|c|c|c|c|c|c|c|c|}
\hline \multirow{3}{*}{ Sikap Kerja Duduk } & \multicolumn{10}{|c|}{ Keluhan Nyeri Punggung } & \multirow{3}{*}{$\mathrm{P}$ value } \\
\hline & \multicolumn{2}{|c|}{ Rendah } & \multicolumn{2}{|c|}{ Sedang } & \multicolumn{2}{|c|}{ Tinggi } & \multicolumn{2}{|c|}{$\begin{array}{l}\text { Sangat } \\
\text { Tinggi }\end{array}$} & \multicolumn{2}{|c|}{ Jumlah } & \\
\hline & $\mathrm{n}$ & $\%$ & $\mathrm{n}$ & $\%$ & $\mathrm{~N}$ & $\%$ & $\mathrm{n}$ & $\%$ & $\mathrm{n}$ & $\%$ & \\
\hline Tidak Risiko & 0 & 0 & 0 & 0 & 0 & 0 & 0 & 0 & 0 & 0 & \multirow{5}{*}{0,010} \\
\hline Risiko Rendah & 3 & 50 & 3 & 50 & 0 & 0 & 0 & 0 & 6 & 100 & \\
\hline Risiko Sedang & 19 & 67,9 & 9 & 32,1 & 0 & 0 & 0 & 0 & 28 & 100 & \\
\hline Risiko Tinggi & 7 & 50 & 7 & 50 & 0 & 0 & 0 & 0 & 14 & 100 & \\
\hline $\begin{array}{c}\text { Risiko Sangat } \\
\text { Tinggi }\end{array}$ & 1 & 9,1 & 10 & 90,9 & 0 & 0 & 0 & 0 & 11 & 100 & \\
\hline Jumlah & 30 & 50,8 & 29 & 49,2 & 0 & 0 & 0 & 0 & 59 & 100 & \\
\hline
\end{tabular}

Berdasarkan tabel 3 didapatkan hasil bahwa responden dengan sikap kerja duduk dalam kategori risiko rendah yaitu 3 orang (50\%) mengalami keluhan nyeri punggung dalam kategori rendah, sikap kerja duduk dalam kategori risiko sedang yaitu 19 orang $(67,9 \%)$ mengalami keluhan nyeri punggung dalam kategori rendah, sikap kerja duduk dalam kategori resiko tinggi yaitu 7 orang (50\%) mengalami keluhan nyeri punggung dalam kategori rendah dan sikap kerja duduk dalam kategori sangat tinggi yaitu 10 orang $(90,9 \%)$ mengalami keluhan nyeri punggung dalam kategori sedang,

Berdasarkan analisa data yang menggunakan uji korelasi spearman rho menunjukan bahwa nilai $\mathrm{p}$ value $=0,010$, maka $\mathrm{p}$ value $<\alpha(0,05)$ berarti Ho ditolak artinya ada hubungan yang signifikan antara sikap kerja duduk dengan keluhan nyeri punggung bawah pada pekerja yang menggunakan komputer di Kantor Kesehatan Pelabuhan Kelas II Bandung tahun 2017.

\section{PEMBAHASAN}

\section{Sikap Kerja Duduk}

Berdasarkan hasil penelitian menunjukkan bahwa responden dengan sikap kerja duduk dalam kategori rendah yaitu 6 orang $(10,2 \%)$, sedang yaitu 28 orang $(47,5)$, tinggi yaitu 14 orang $(23,7)$ dan sangat tinggi yaitu 11 orang $(18,6 \%)$. Hal ini menunjukkan kebanyakan responden dengan sikap kerja duduk dalam kategori sedang.

Posisi netral (duduk dan berdiri secara normal) merupakan kondisi yang paling alamiah untuk bekerja, dengan usaha otot dan tekanan pada sendi, tendon, dan ligamen yang paling minimum. Banyak pekerjaan yang memaksa pekerjanya dengan posisi bungkuk, jongkok, atau sikap kerja dengan pergelangan tangan menekuk dan leher mendongak. Sikap kerja tersebut sangat berisiko berdampak pada gangguan sistem otot-rangka. ${ }^{13}$

Hasil penelitian ini sejalan dengan penelitian Wijayanti (2013) yang menunjukkan bahwa responden dengan posisi kerja duduk yang berisiko sedang sebanyak 31 orang $(86,1 \%)$ dan 5 orang $(13,9 \%)$ berisiko tinggi. ${ }^{14}$ Hasil penelitian Wulandari (2016) juga menunjukkan bahwa postur kerja duduk $75 \%$ responden termasuk dalam risiko sedang dengan jumlah 57 responden. ${ }^{15}$ Posisi kerja duduk yang tidak ergonomis dapat menimbulkan keluhan pada otot-otot skeletal, salah satunya adalah nyeri punggung bawah.

Berdasarkan uraian di atas dapat disimpulkan bahwa sebagian besar responden dengan sikap kerja duduk dalam kategori sedang. Posisi kerja yang berisiko dapat menimbulkan keluhan nyeri pada bagian tubuh pekerja karena pekerjaan yang dilakukan secara berulang-ulang dalam jangka waktu yang lama akan meningkatkan risiko gangguan 
pada sistem otot rangka.

\section{Keluhan Nyeri Punggung Bawah}

Berdasarkan hasil penelitian menunjukkan bahwa responden dengan keluhan nyeri punggung bawah dalam kategori rendah yaitu 30 orang $(50,8 \%)$ dan sedang yaitu 29 orang $(49,2 \%)$. Hal ini menunjukkan bahwa lebih dari setengah responden dengan keluhan nyeri punggung bawah dalam kategori rendah.

Salah satu penyebab nyeri punggung adalah bergesernya bantalan tulang belakang sehingga menekan saraf belakang. Sendi atau ruas tulang belakang memiliki komponen inti yang disebut nucleus yang berbentuk seperti agar-agar dan berfungsi sebagai bantalan dan peredam kejut. Kondisi ini menimbulkan sakit yang luar biasa. Penyebab lain nyeri punggung adalah spondilosis, yakni kerusakan pada sendi tulang belakang (intervetebral disc) akibat aus atau terkikisnya tulang rawan yang melindungi ruas tulang belakang. ${ }^{13}$

Hasil penelitian ini sejalan dengan penelitian Wijayani (2013) yang menunjukkan bahwa 23 orang $(63,9 \%)$ mengalami keluhan nyeri pinggang ringan dan 13 orang $(36,1 \%)$ mengalami keluhan nyeri pinggang sedang. ${ }^{14}$ Hasil penelitian Wulandari (2013) juga menunjukkan bahwa keluhan nyeri musculoskeletal pada $75 \%$ responden termasuk dalam risiko sedang dengan jumlah 57 responden. ${ }^{15}$ Hal tersebut disebabkan karena sebagian besar posisi kerja duduk responden yang tidak ergonomis, sehingga menyebabkan keluhaan nyeri pinggang pada responden.

Berdasarkan uraian di atas dapat disimpulkan bahwa lebih dari sebagian responden mengalami keluhan nyeri punggung bawah dalam kategori rendah. Bekerja pada posisi kerja duduk yang salah dapat menimbulkan berbagai masalah kesehatan salah satunya yaitu keluhan nyeri punggung bawah.

\section{Hubungan Sikap Kerja Duduk Dengan Keluhan Nyeri Punggung Bawah}

Hasil penelitian menunjukkan bahwa responden dengan sikap kerja duduk dalam kategori rendah yaitu 3 orang (50\%) mengalami keluhan nyeri punggung dalam kategori rendah, sikap kerja duduk dalam kategori sedang yaitu 19 orang (67,9\%) mengalami keluhan nyeri punggung dalam kategori rendah, sikap kerja duduk dalam kategori tinggi yaitu 7 orang (50\%) mengalami keluhan nyeri punggung dalam kategori rendah da sikap kerja duduk dalam kategori sangat tinggi yaitu 10 orang $(90,9 \%)$ mengalami keluhan nyeri punggung dalam kategori sedang. Berdasarkan analisa data yang menggunakan uji korelasi spearman rho menunjukan bahwa nilai $\mathrm{p}$ value $=0,010$, maka $\mathrm{p}$ value $<\alpha(0,05)$ berarti Ho ditolak artinya ada hubungan yang signifikan antara sikap kerja duduk dengan keluhan nyeri punggung bawah pada pekerja yang menggunakan komputer di Kantor Kesehatan Pelabuhan Kelas II Bandung tahun 2017.

Salah satu penyakit akibat kerja (PAK) adalah nyeri punggung bawah atau Low Back Pain (LBP) yang disebabkan oleh posisi duduk yang salah pada saat bekerja yaitu sindroma klinik yang ditandai dengan gejala utama nyeri atau perasaan lain yang tidak enak didaerah tulang punggung bagian bawah. ${ }^{2}$ Nyeri punggung bawah merupakan fenomena yang seringkali dijumpai pada setiap pekerjaan. Insiden dan beratnya gangguan nyeri punggung bawah lebih sering dijumpai pada pekerja wanita dibandingkan laki-laki. Posisi statis dalam bekerja kadang-kadang tidak dapat terhindarkan. Bila keadaan statis tersebut berlangsung terus-menerus atau berulang-ulang maka dapat menyebabkan gangguan kesehatan antara lain nyeri punggung bawah. Nyeri punggung bawah yang timbul dapat mengakibatkan kehilangan jam kerja sehingga menggangu produktivitas kerja. ${ }^{3}$

Penyusunan tempat kerja dan tempat duduk yang sesuai harus diatur sedemikian sehingga tidak ada pengaruh yang berbahaya bagi kesehatan. Tempat-tempat duduk yang cukup dan sesuai harus disediakan untuk pekerja-pekerja dan pekerja harus diberi 
kesempatan yang cukup untuk menggunakannya. Cara bekerja harus diatur sedemikian rupa sehingga tidak menimbulkan ketegangan otot, kelelahan yang berlebihan atau gangguan kesehatan yang lain. ${ }^{8}$

Bekerja pada kondisi yang tidak ergonomis dapat menimbulkan berbagai masalah, antara lain: nyeri, kelelahan bahkan kecelakaan. Hal ini didukung hasil penelitian Sakinah (2012) menyatakan bahwa terdapat hubungan antara sikap tubuh dengan keluhan nyeri punggung bawah. ${ }^{4}$ Hasil penelitian Tangkeallo (2013) juga menyatakan bahwa posisi duduk memiliki hubungan yang bermakna dengan keluhan nyeri punggung bawah. ${ }^{9}$ Hasil penelitan Hidayat (2013) juga menyimpulkan bahwa faktor risiko ergonomi dapat mempengaruhi munculnya keluhan muskuloskeletal terhadap pekerja. Semakin tidak ergonomis suatu pekerjaan maka akan memicu terjadinya keluhan muskuloskeletal dengan tingkat keluhan lebih tinggi. Oleh karena itu di tempat kerja perlu diterapkan sistem kerja secara ergonomis. ${ }^{1}$

Berdasarkan hasil penelitian maka dapat disimpulkan bahwa sikap kerja duduk dapat mempengaruhi keluhan nyeri punggung bawah pada pekerja yang menggunakan komputer. Keluhan nyeri punggung bawah pada responden disebabkan oleh posisi kerja duduk yang berisiko, duduk lama dengan posisi yang salah akan menyebabkan otot-otot punggung bawah menjadi tegang dan dapat merusak jaringan lunak sekitarnya.

\section{SIMPULAN}

1. Sikap kerja duduk dalam kategori risiko rendah yaitu 6 orang $(10,2 \%)$, risiko sedang yaitu 28 orang $(47,5)$, risiko tinggi yaitu 14 orang $(23,7)$ dan risiko sangat tinggi yaitu 11 orang $(18,6 \%)$.

2. Keluhan nyeri punggung bawah dalam kategori rendah yaitu 30 orang $(50,8 \%)$ dan sedang yaitu 29 orang $(49,2 \%)$.

3. Uji spearman rho menunjukan bahwa nilai $\mathrm{p}$ value $=0,010$, maka $\mathrm{p}$ value $<\alpha(0,05)$ berarti Ho ditolak artinya ada hubungan yang signifikan antara sikap kerja duduk dengan keluhan nyeri punggung bawah pada pekerja yang menggunakan komputer.

\section{SARAN}

1. Bagi Instansi Penelitian

1) Hendaknya menyediakan alat operasional kerja yang ergonomis seperti tempat duduk yang bisa disesuaikan ketinggiannya, sehingga bisa mengurangi beban punggung dalam bekerja.

2) Melakukan analisis beban kerja terhadap pegawai secara berkala, dengan beban kerja yang sesuai bisa mengurangi waktu lembur kerja pegawai.

2. Bagi Pekerja

Hendaknya memperhatikan sikap kerja duduk yang sesuai dan rileks dalam bekerja agar terhindar dari sikap-sikap tidak alamiah yang dapat mempengaruhi kesehatan.

3. Bagi Institusi Pendidikan

Hasil penelitian ini diharapkan dapat menambah khasanah kepustakaan serta bisa dijadikan bahan referensi dalam proses pembelajaran bidang kesehatan khususnya tentang antara sikap kerja duduk dengan keluhan nyeri punggung bawah pada pekerja yang menggunakan komputer.

4. Bagi Peneliti Selanjutnya

Diharapkan pada peneliti lain agar mengembangkan penelitian ini dengan memperhatikan faktor-faktor lainya yang mempengaruhi keluhan nyeri punggung bawah seperti beban kerja, riwayat penyakit dan lain sebagainya serta keluhan-keluhan lain yang mungkin ditimbulkan. 


\section{DAFTAR PUSTAKA}

1. Hidayat, T. Hubungan Faktor Risiko Ergonomi dan Individu dengan Keluhan Muskuloskeletal pada Karyawan Bagian Produksi PT. Family Raya Kota Padang. 2013. [Diakses pada tanggal 25 November 2016]. Diunduh dari http://www.bimkes.org/wpcontent/uploads/downloads/2014/02/BIMKMI\%20Volume\%202\%20Edisi\%201.pdf.

2. Basuki K. Faktor Risiko Kejadian Low Back Pain Pada Operator Tambang Sebuah Perusahaan Tambang Nickel di Sulawesi Selatan. 2009. [Diakses pada tanggal 25 November 2016]. Diunduh dari http://ejournal.undip.ac.id/index.php/jpki/article/download/2346/2068.

3. Samara, D. Sikap Membungkuk dan Memutar Selama Bekerja Sebagai Faktor Risiko Nyeri Punggung Bawah. 2005. [Diakses pada tanggal 25 November 2016] Diunduh dari. http://www.univmed.org/wp-content/uploads/2011/02/Diana_dkk.pdf.

4. Sakinah. Faktor Yang Berhubungan Dengan Keluhan Nyeri Punggung Bawah Pada Pekerja Batu Bata Di Kelurahan Lawawoi Kabupaten Sidrap. 2015. [Diakses pada tanggal 25 November 2016]. Diunduh dari. http://repository.unhas.ac.id/bitstream/handle/123456789/6701/JURNAL.pdf?sequence=1. 5. Santoso, G. Ergonomi Terapan. Edisi Pertama. Jakarta; Prestasi Pustaka Raya; 2013.

6. Smeltzer, \& Bare. Buku Ajar Keperawatan Medical Bedah Brunner \& Suddart. Edisi 8, Vol 1, Alih Bahasa: Kuncara Monica Ester. Jakarta: EGC; 2005.

7. Budiono, S. Bunga Rampai Hiperkes \& KK. Semarang: Universitas Diponegoro;2009.

8. ILO (International Labour Organization). Keselamatan dan Kesehatan Kerja di Tempat Kerja. 2013. [Diakses pada tanggal 25 November 2016]. Diunduh dari http://www.ilo.org/wcmsp5/groups/public/---asia/---ro-bangkok/---ilojakarta/documents/publication/wcms_237650.pdf.

9. Tangkeallo, C.M. Hubungan Posisi Duduk Dengan Keluhan Nyeri Punggung Bawah Pada Sopir Kakmu Unhas. 2013. [Diakses pada tanggal 25 November 2016]. Diunduh dari http://repository.unhas.ac.id/bitstream/handle/123456789/14045/CINDY\%20MITRA.pdf? sequence $=1$

10. Tarwaka. Ergonomi Untuk Keselamatan, Kesehatan Kerja dan Produktivitas, Surakarta: UNIBA PRESS;2014.

11. Notoatmodjo. Metodologi Penelitian Kesehatan. Jakarta: Rineka Cipta; 2010.

12. Suhardi B. Perancang Sistem Kerja Dan Ergonomi Industri. Jakarta: Pusat Perbukuaan, Departemen Pendidikan Nasional. 2008. [Diakses pada tanggal 1 Desember 2016]. Diunduh dari https://aguseducated.files.wordpress.com/2011/04/54-perancangan-sistemkerja-dan-ergonomi-industri-jilid-1.pdf.

13. Jeyaratnam, J., dan Koh, D. Buku Ajar Praktik Kedokteran Kerja, Jakarta: EGC; 2010.

14. Wijayanti, T. Hubungan Antara Posisi Kerja Duduk Dengan Keluhan Subyektif Nyeri Pinggang Pada Penjahit Garment di PT. Apac Inti Corpora Kabupaten Semarang 2013. [Diakses pada tanggal 1 Desember 2016]. Diunduh dari. http://eprints.dinus.ac.id/6456/1/jurnal_11880.pdf.

15. Wulandari, D.U. Hubungan Antara Risiko Postur Kerja Dengan Risiko Keluhan Muskuloskeletal Pada Pekerja di Bagian Produksi Tenun PT. Kusuma Mulia Plasindo Infitex Klaten. 2016. [Diakses pada tanggal 1 Desember 2016]. Diunduh dari. http://eprints.ums.ac.id/48205/3/NASKAH\%20PUBLIKASI\%20fix.pd 